\title{
Farklı Besi Zamanlarındaki Ultrasonik Ölçümler ile Karkas Özellikleri Arasındaki İlişkilerin Belirlenmesi
}

\author{
Yasin ALTAY ${ }^{*}$, Ali KARABACAK ${ }^{2}$, İbrahim AYTEKİN ${ }^{2}$ \\ ${ }^{1}$ Eskişehir Osmangazi Üniversitesi, Ziraat Fakültesi, Zootekni Bölümü, Eskişehir, TÜRKİYE \\ ${ }^{2}$ Selçuk Üniversitesi, Ziraat Fakültesi, Zootekni Bölümü, Konya, TÜRKIYYE
}

\begin{tabular}{l}
\hline Geliş Tarihi/Received: $17.04 .2020 \quad$ Kabul Tarihi/Accepted: 30.06 .2020 \\
\hline ORCID ID (Yazar sirasina göre / by author order) \\
(D) orcid.org/0000-0003-4049-8301 (D) orcid.org/0000-0002-7710-9106 (D)orcid.org/0000-0001-7769-0685 \\
${ }^{*}$ Sorumlu Yazar/Corresponding Author: yaltay@ogu.edu.tr
\end{tabular}

Öz: Bu çalışma, Akkaraman kuzularının farklı entansif besi sürelerinde ultrasonik ölçümler ile karkas özellikleri arasındaki ilişkileri çok değişkenli bir korelasyonla (kanonik) tahmin etmek amacıyla yapılmıştır. Bu amaçla yaklaşık 2.5 aylık yaşta ortalama $20 \mathrm{~kg}$ canlı ağırlıkta 16 adet erkek Akkaraman kuzuları besiye alınmış, 10 günlük alıştırma periyodu ve 70 günlük entansif besi sonunda kesime gönderilmiştir. Hayvanlara besi süresince $150 \mathrm{~g}$ kuru yonca otu ve ad-libitum olarak kesif yem verilmiștir. Besi başı, ortası ve sonundaki ultrasonik ölçümler olarak göz kası derinliğ̣i, göz kası üstü yağ kalınlığı ile deri kalınlığı bağımsız değişken veri seti olarak alınırken, karkas özellikleri ise bağımlı değişken veri seti olarak alınmıştır. Sonuç olarak Akkaraman kuzularının besi başında kanonik korelasyon katsayıları 0.999, 0.977 ve 0.549 iken; besi ortasında 0.980 , 0.931 ve 0.770 , besi sonunda ise $0.999,0.996$ ve 0.814 olarak belirlenmiștir. Besi başında ilk kanonik korelasyon katsayıları ve besi sonunda birinci ve ikinci kanonik korelasyon katsayıları istatistik olarak önemli iken $(\mathrm{P}<0.05)$, besi ortasındaki kanonik korelasyon katsayıları istatistik olarak önemli olmadıkları saptanmıştır. Sonuç olarak, Akkaraman kuzularının besi süresince alınan ultrasonik ölçümlerinin karkas özelliklerinin tahmininde kullanılabileceği tespit edilmiștir.

Anahtar Kelimeler: Akkaraman, kanonik korelasyon, kanonik değişken, karkas özellikleri, çok değişkenli analiz, ultrasonik ölçümler

\section{Determination of the Relationship Between Ultrasonic Measurements at Different Fattening Times and Carcass Properties}

\begin{abstract}
This study was conducted to estimate the relationships between the ultrasonic measurements and carcass characteristics of Akkaraman lambs at different intensive feeding periods with a multivariate correlation (canonical). For this purpose, 16 male Akkaraman lambs with an average of $20 \mathrm{~kg}$ live weight at the age of 2.5 months were fed and sent to slaughter after a 10-day training period and 70-day intensive feeding. The lambs were fed with $150 \mathrm{~g}$ of dry alfalfa and concentrated feed as ad-libitum during the fattening period. As the ultrasonic measurements were taken at the beginning, middle, and the end of the fattening, eye muscle depth, eye muscle fat thickness, and skin thickness were taken as independent variable data set, while carcass characteristics were taken as dependent variable data set. As a result, the canonical correlation coefficients of Akkaraman lambs were 0.999, 0.977, and 0.549 at the beginning of fattening; 0.980, 0.931 , and 0.770 in the middle of the fattening and $0.999,0.996$ and 0.814 at the end of the fattening, respectively. While the first coefficient of canonical correlation at the beginning of the fattening and the first and second coefficient of canonical correlation at the end of the fattening was statistically significant $(\mathrm{P}<0.05)$, it was found that the coefficients of canonical correlation in the middle of the fattening were not statistically significant. As a result, it has been determined that the ultrasonic measurements taken during the fattening of Akkaraman lambs can be used to estimate the carcass characteristics.
\end{abstract}

Keywords: Akkaraman, canonical correlation, canonical variable, carcass measurement, multivariate analysis, ultrasonic measurements 


\section{Giriş}

Kasaplık hayvanlar her ne kadar farklı pazar isteklerine uygun olarak yetiştirilseler de, üreticilerin gelirlerinin büyük kısmı bu faaliyetin sonucunda oluşmaktadır. Hayvanların canlı iken karkas özelliklerinin erken çağda belirlenmesi ekonomik seviyede oldukça önem arz etmektedir. Canlı hayvanlarda karkas özelliklerinin belirlenmesinde subjektif yöntemlerin yanı sıra, sofistik ve ultrasonik yöntemler de kullanılmaktadır (Kor ve Ertuğrul, 2000).

Ultrason teknolojisi canlı hayvanlarda karkasın durumunu (karkas kompozisyonu ve kalitesi) belirlemek için hızlı, hayvana zarar vermeden ve ekonomik bir şekilde tahmin edilmesi için kullanılan bir metot olarak yetiştirme programlarında yerini gün geçtikçe almaktadır. Yağsız et içeriğinin tahmin edilmesinde ultrasonik tekniklerin diğer subjektif olarak geliştirilen kondüsyon derecelendirmesinden daha isabetli olduğunu belirlenmiştir (Croston ve Owen, 1992). Göz kası alanı (MLD) bölgesinden alınan ultrasonik ölçülerin, diğer bazı metotlara göre gerçek ölçülere daha uyumlu olduğu tespit edilmiştir (Simm, 1983). Ultrason ölçümleri ile ele alınan özellikler arasında yüksek bir korelasyon ve doğruluk elde edilen parametreler, yetiştirme programlarında güvenilir bir şekilde kullanımlarını arttırmaktadır. Burada dikkat edilmesi gereken nokta, doğru noktadan hassas ölçümlerin ve uygun istatistik analizlerinin yapılmasidir.

$\mathrm{Bu}$ kapsamda ele alınan özelliklerin farklı zaman ve sayıda olması değerlendirme yapmayı karmaşık hale getirmiştir. Hayvanlar canlı iken karkas özelliklerinin tahmin edilmesi veya erken bir seleksiyon kriterinin karkas özellikleriyle ilişkilerinin araştırılması sonucu ortaya çıkmaktadır. Erken seleksiyon kriterlerinin ve karkas özelliklerinin birden fazla oluşu çok değişkenli bir ilişkinin söz konusu olduğunu göstermektedir.

İki özellik arasındaki doğrusal ilişkinin yönü ve derecesi Pearson korelasyon katsayısı yardımıyla belirlenirken; iki veri seti arasındaki ilişki, kanonik korelasyon katsayısı yardımıyla tespit edilmektedir. İki veri seti arasındaki ilişkilerin belirlenmesinde ise genelleştirilmiş moment fonksiyonundan yararlanılmaktadır (Hotelling, 1936; Baggaley, 1981). Kanonik korelasyon, veri setlerinin doğrusal kombinasyonlarından oluşan kanonik değişkenlerin arasındaki korelasyondur. Bağımlı ve bağımsız değişken setinde bulunan minimum değişken sayısı kadar kanonik korelasyon katsayısı hesaplanır (Koşkan ve ark., 2011).
$\mathrm{Bu}$ bakımdan bu çalışmada, Akkaraman kuzularında besi başı, ortası ve sonu alınan ultrasonik ölçümler seti ile karkas özellikleri setlerindeki özellikleri arasındaki ilişkinin kanonik korelasyon analizi ile tespit edilmesi ve ultrasonik ölçümlerin besinin hangi döneminde almanın daha doğru olacağı yönünde bir yaklaşım ortaya koymak amaçlanmıştır.

\section{Materyal ve Yöntem}

\subsection{Materyal}

Bu çalışmanın materyalini; Selçuk Üniversitesi, Ziraat Fakültesi, Prof. Dr. Orhan DÜZGÜNEŞ Araştırma ve Uygulama Çiftliği küçükbaş biriminde besiye alınan 16 baş erkek Akkaraman kuzuları oluşturmuştur. Kuzular yaklaşık 2.5 aylık yaşta ortalama $20 \mathrm{~kg}$ canlı ağırlıkta besiye alınmış, 10 günlük alıştırma periyodu ve 70 günlük entansif besi sonunda kesime gönderilmiştir. Hayvanlara besi süresince $150 \mathrm{~g}$ kuru yonca otu ve ad-libitum olarak kesif yem verilmiştir.

\subsection{Yöntem}

Çalışmada besi sonunda kesim öncesi göz kası derinliği, göz kası üstü yağ kalınlığ 1 ve deri kalınlığ 1 gibi ultrasonik ölçümler 12. ve 13. kaburgalar aras1 bölgede prob ile belirlenmiştir. Canlı ağırlıklar $10 \mathrm{~g}$ hassasiyetli terazi ile belirlenmiştir. İlk değişken setlerinde besi başı, ortası ve sonu ayrı ayrı olmak üzere ultrasonik parametreler bulunurken, ikinci değişken setinde karkas özellikleri bulunmaktadır. Ele alınan bu değişken setleri arasında çok değiş̧kenli ilişkinin varlığı araştırılmıştır.

İki özellik arasındaki ilişkinin yönü, derecesi ve şiddetini ölçmek için doğrusal veya doğrusal olmayan korelasyon katsayılarından yararlanılır. Birden fazla özelliğin aynı anda değişken setleri arasındaki ilişkinin derecesinin belirlenmesinde çok değişkenli istatistiğe ihtiyaç duyulmaktadır.

Ele alınan değişkenlerin doğrusal kombinasyonlarından oluşan yeni değişkenlere kanonik değişkenler ve bunlar arasındaki korelasyon katsayısına ise kanonik korelasyon adı verilir (Gürbüz, 1989; Tatlıdil, 1996; Kocabaş ve ark., 1998; Ferreira ve Purcell, 2009; Karabacak ve ark., 2009; Keskin ve Dağ, 2009; Koşkan ve ark., 2011; Tang ve Ferreira 2012). Ayrıca kanonik korelasyon analizi, diğer tüm tek değişkenli ve çok değişkenli özellikleri içeren en genel doğrusal model olarak ta tanımlanmaktadır (Kerlinger ve Pedhazur, 1973; Thompson, 1984).

İlk setteki değişkenler $X_{1}, X_{2}, \ldots \ldots \ldots X_{p}$ ve ikinci setteki değişkenler $\mathrm{Y}_{1}, \mathrm{Y}_{2}, \ldots \ldots \ldots \ldots \mathrm{Y}_{\mathrm{q}}$ olarak tanımlanırsa bunların doğrusal 
kombinasyonları Eşitlik 1 ve 2'deki gibidir (Tatsuoka, 1971; Sharma, 1996; Özdamar, 2004; Mendes ve ark., 2005; Çankaya ve Kayaalp, 2007; Koşkan ve ark., 2011; Takma ve ark., 2017; Karabacak ve ark., 2019).

$$
\begin{aligned}
& \mathrm{Z}=\mathrm{U}_{1} \mathrm{X}_{1}+\mathrm{U}_{2} \mathrm{X}_{2}+\ldots \ldots \ldots \ldots . .+\mathrm{U}_{\mathrm{P}} \mathrm{X}_{\mathrm{P}} \\
& \mathrm{W}=\mathrm{V}_{1} \mathrm{Y}_{1}+\mathrm{V}_{2} \mathrm{Y}_{2}+\ldots \ldots \ldots \ldots \ldots . .+\mathrm{VqYq}
\end{aligned}
$$

Burada $Z$ ve $W$, kanonik değişkenler; $U_{i}$ ve $V_{i}$, kanonik değişkenlerin katsayıları; $\mathrm{X}_{\mathrm{i}}$ ve $\mathrm{Y}_{\mathrm{i}}$ ise değişkenlerin doğrusal kombinasyonlarıdır.

Katsayı matrisleri $U=\left[\mathrm{U}_{1}, \mathrm{U}_{2} \ldots . . \mathrm{Up}\right]$ ve $\mathrm{V}=\left[\mathrm{V}_{1}, \mathrm{~V}_{2} \ldots \ldots . \mathrm{Vq}\right]$ olarak ifade edildiğinde, iki doğrusal kombinasyon arasındaki en büyük kombinasyon olarak U ve V'nin bir fonksiyonu olup $\mathrm{r}_{\mathrm{zw}}$ şeklinde tanımlanır (Johnson ve Wichern, 2002; Özkan ve ark., 2008; Koşkan ve ark., 2011). Eşitlik 3 yardımıyla hesaplanan kanonik korelasyon katsayılarının hipotez kontrolü $\chi^{2}$ ve F testlerinden biri yardımıyla kontrol edilir. $\chi^{2}$ Eşitlik 4 yardımıyla hesaplanır.

$$
\begin{aligned}
& r_{z w}=\frac{u^{\prime} \sum 12 v}{\sqrt{\left.u^{\prime} \sum 11 v\right)\left(u^{\prime} \sum 22 v\right)}} \\
& \chi^{2}=-[n-0.5(p+q+1)] * \ln \Lambda
\end{aligned}
$$

Burada $n$, gözlem sayısını; $p$, birinci setteki değişken sayısını; $q$, ikinci setteki değişken sayısını; $\Lambda,\left(1-\mathrm{R}_{\mathrm{m} 1}^{2}\right) *\left(1-\mathrm{R}_{\mathrm{m} 2}^{2}\right)^{*} \ldots \ldots \ldots \ldots *\left(1-\mathrm{R}_{\mathrm{mn}}\right)^{\prime} \mathrm{yi}$ ifade eder. $\chi^{2}$ test istatistik değeri ise $\mathrm{p}^{*} \mathrm{q}$ serbestlik dereceli $\chi^{2}$ kritik tablo değerinden elde edilen değerle karşıllaştırılır (Keskin ve ark., 2005; Koşkan ve ark., 2011). Redundancy indeksi Eşitlik 5 yardımı ile hesaplanır.

$$
\mathrm{AU}\left(\frac{\mathrm{Y}}{\mathrm{V}_{\mathrm{i}}}\right)=\sum \mathrm{L} * \mathrm{Y}_{\mathrm{ij}}^{2} / \mathrm{q}
$$

$\mathrm{Bu}$ eşitlikte $\mathrm{AU}(\mathrm{Y} / \mathrm{Vi}), \mathrm{Y}$ değişken setinde i. kanonik değişken ile açıklanabilen ortalama varyansı; $L * Y_{i j}, Y$ değişken setindeki j. değişken ile i. kanonik değişken arasındaki korelasyonu; q, Y değişken setindeki değişken sayısını ifade etmektedir (Koşkan ve ark., 2011).

\section{Bulgular ve Tartışma}

Çalışmada, Akkaraman kuzularına ait karkas özelliklerden besi başı $\left(\mathrm{X}_{1}\right)$, ortası $\left(\mathrm{X}_{2}\right)$ ve sonunda $\left(\mathrm{X}_{3}\right)$ belirlenen göz kası derinliği (KD), göz kası üstü yağ kalınlığ 1 (YK) ve deri kalınlığ1 (DK) gibi ultrasonik ölçümler (X1, X2, X3 setleri) ve karkas ağırlığı (KA), soğuk karkas ağırlığ1 (SKA), karkas randımanı (KR), kuyruk ağırlığı (KUYA), but ağırlığ1 (BA), omuz başı ağırlığ1 (OBA), kol ağırlığ1 (KOLA), etek ağırlığı (EA), göz kası üstü kabuk yağı kalınlığı (GKKYK), kaburga üstü kabuk yağı kalınlığı (KUKYK) ve göz kası alanı karkas (MLD) özelliklerine (Y seti) ait tanımlayıcı istatistikler Tablo 1'de ve ele alınan özellikler arasındaki Pearson korelasyonlar ise Tablo 2'de verilmiştir.

\begin{tabular}{|c|c|c|c|c|c|c|}
\hline Veri seti & Özellikler & $\mathrm{n}$ & Minimum & Maksimum & $\bar{X} \pm S_{\bar{x}}$ & $S_{x}$ \\
\hline \multirow{3}{*}{$X_{1}$} & $\mathrm{KD}_{1}$ & 16 & 1.671 & 2.291 & $1.943 \pm 0.050$ & 0.199 \\
\hline & $\mathrm{YK}_{1}$ & 16 & 0.108 & 0.292 & $0.200 \pm 0.011$ & 0.042 \\
\hline & $\mathrm{DK}_{1}$ & 16 & 0.194 & 0.254 & $0.224 \pm 0.005$ & 0.020 \\
\hline \multirow{3}{*}{$\mathrm{X}_{2}$} & $\mathrm{KD}_{2}$ & 16 & 1.509 & 2.499 & $2.054 \pm 0.067$ & 0.270 \\
\hline & $\mathrm{YK}_{2}$ & 16 & 0.189 & 0.401 & $0.298 \pm 0.017$ & 0.067 \\
\hline & $\mathrm{DK}_{2}$ & 16 & 0.253 & 0.427 & $0.333 \pm 0.011$ & 0.043 \\
\hline \multirow{3}{*}{$\mathrm{X}_{3}$} & $\mathrm{KD}_{3}$ & 16 & 1.945 & 2.685 & $2.328 \pm 0.060$ & 0.239 \\
\hline & $\mathrm{YK}_{3}$ & 16 & 0.197 & 0.437 & $0.318 \pm 0.019$ & 0.075 \\
\hline & $\mathrm{DK}_{3}$ & 16 & 0.282 & 0.448 & $0.357 \pm 0.011$ & 0.046 \\
\hline \multirow{11}{*}{$\mathrm{Y}$} & $\mathrm{KA}$ & 16 & 35.441 & 47.009 & $41.472 \pm 0.789$ & 3.156 \\
\hline & SKA & 16 & 16.069 & 22.869 & $19.881 \pm 0.530$ & 2.119 \\
\hline & KR & 16 & 43.965 & 52.841 & $48.455 \pm 0.445$ & 1.779 \\
\hline & KUYA & 16 & 1.610 & 3.827 & $2.682 \pm 0.165$ & 0.661 \\
\hline & BA & 16 & 2.495 & 3.583 & $2.982 \pm 0.075$ & 0.300 \\
\hline & OBA & 16 & 0.412 & 0.710 & $0.524 \pm 0.020$ & 0.0784 \\
\hline & KOLA & 16 & 1.301 & 1.780 & $1.553 \pm 0.034$ & 0.137 \\
\hline & EA & 16 & 0.858 & 1.240 & $1.068 \pm 0.028$ & 0.1131 \\
\hline & GKKYK & 16 & 1.544 & 4.356 & $2.608 \pm 0.211$ & 0.842 \\
\hline & KUKYK & 16 & 3.066 & 8.486 & $5.229 \pm 0.316$ & 1.266 \\
\hline & MLD & 16 & 11.953 & 22.423 & $16.774 \pm 0.829$ & 3.316 \\
\hline
\end{tabular}

Ultrasonik ölçümlerin besi sonuna doğru arttı̆̆1 tespit edilmiştir. Besi başlangıcındaki göz kası, göz kası üstü yağ kalınlığı ve deri kalınlığı değerleri

Tablo 1. Akkaraman kuzularına ait $X_{1,2,3}$ ve $Y$ setlere ait bazı tanıtıcı istatistikler

n: Gözlem adeti, $\bar{X}$ : İncelenen özelliklerin ortalaması, $\mathrm{S}_{\overline{\mathrm{X}}}$ : Özelliklerin standart hatası, $\mathrm{S}_{\mathrm{X}}$ : Özelliklerin standart sapması, $\mathrm{KD}_{1}$ : Besi başlangıcındaki göz kası derinliği, $\mathrm{YK}_{1}$ : Besi başlangıcındaki göz kası üstü yağ kalınlığı, $\mathrm{DK}_{1}$ : Besi başlangıcındaki deri kalınlığı, $\mathrm{KD}_{2}$ : Besi ortasındaki göz kası derinliği, $\mathrm{YK}_{2}$ : Besi ortasındaki göz kası üstü yağ kalınlığı, $\mathrm{DK}_{2}$ : Besi ortasındaki deri kalınlığı, $\mathrm{KD}_{3}$ : Besi sonundaki göz kası derinliği, $\mathrm{YK}_{3}$ : Besi sonundaki göz kası üstü yağ kalınlığı, $\mathrm{DK}_{3}$ : Besi sonundaki deri kalınlığı, KA: Karkas ağırlı̆̆ı, SKA: Soğuk karkas ağırlığı, KR: Karkas randımanı, KUYA: Kuyruk ağırlığı, BA: But ağırlığı, OBA: Omuz başı ağırlığı, KOLA: Kol ağırlığı, EA: Etek ağırlı̆̆ı, GKKYK: Göz kası üstü kabuk yağı kalınlığı, KUKYK: Kaburga üstü kabuk yağı kalınlığı ve MLD: Göz kası alanı 


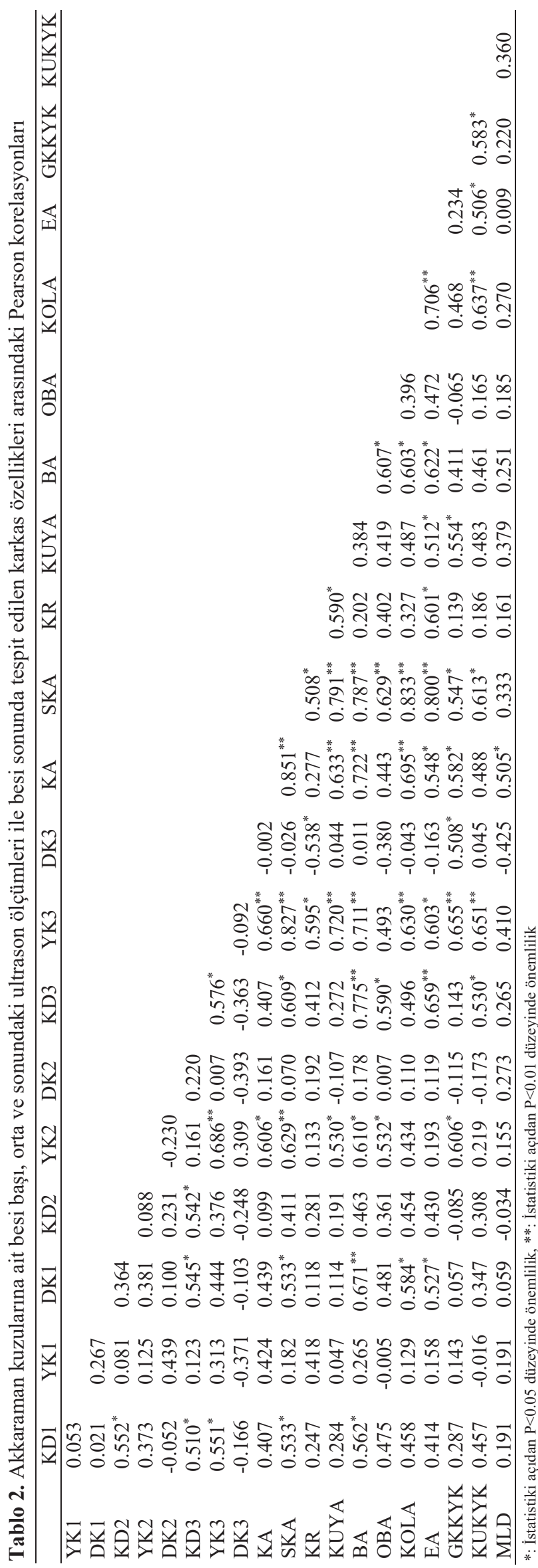


sirasiyla $1.943 \pm 0.050,0.200 \pm 0.011$ ve $0.224 \pm 0.005$ iken; besi sonunda sirasiyla $2.328 \pm 0.060$, $0.318 \pm 0.019$ ve $0.357 \pm 0.011$ değerler aldığ 1 saptanmıştır. Karkas özellikleri için incelenen özellikler; KA, SKA, KR, KUYA, BA, OBA, KOLA, EA, GKKYK, KUKYK ve MLD şeklinde olup sirasiyla; $\quad 41.472 \pm 0.789, \quad 19.881 \pm 0.530$, $48.455 \pm 0.445, \quad 2.682 \pm 0.165, \quad 2.982 \pm 0.075$, $0.524 \pm 0.020, \quad 1.553 \pm 0.034, \quad 1.068 \pm 0.028$, $2.608 \pm 0.211, \quad 5.229 \pm 0.316$ ve $16.774 \pm 0.829$ değerler almıştır (Tablo 1). Karkas özelliklerinin ortalamaya göre standart sapmaları oldukça düşük olması besi alınan Akkaraman kuzularının homojen bir şekilde seçilmiş olmasından kaynaklanmaktadır.

Tablo 2'den de anlaşılacağı üzere, Akkaraman kuzularına ait besi başı ve ortasında belirlenen ultrasonik ölçümler ( $\mathrm{X}_{1}$ ve $\mathrm{X}_{2}$ seti) ile vücut ölçüleri (Y seti) arasındaki Pearson korelasyonlardan 0.70'1 geçemezken; besi sonunda alınan $\mathrm{DK}_{3}$ ile BA (0.775) özellikleri, $\mathrm{YK}_{3}$ ile SKA (0.827), KUYA (0.720) ve BA (0.711) özellikleri arasındaki doğrusal ilişki, istatistik olarak $\mathrm{P}<0.01$ seviyesinde önemli bulunmuştur.

Ayrıca en güçlü doğrusal ilişki KA ile SKA arasındaki 0.851iken, KA ile BA 0.722 olarak tespit edilmiștir. SKA ile KUYA, BA, KOLA ve EA özellikleri arasında sirasıyla $0.791,0.787,0.833$ ve 0.800 korelasyon katsayıları ve bunların önem seviyeleri sahip oldukları belirlenmiştir (Tablo 3).

Birinci kanonik korelasyon katsayısını (maksimum) oluşturan özelliklerin doğrusal kombinasyonu; $\mathrm{Z}_{1}=-0.170 \mathrm{KD}_{1}+0.993 \mathrm{YK}_{1}-$ $0.528 \mathrm{DK}_{1}$ ve $\mathrm{W}_{1}=0.683 \mathrm{KA}+5.215 \mathrm{SKA}+$ $1.451 \mathrm{KR}-2.359 \mathrm{KUYA}-0.793 \mathrm{BA}-1.734 \mathrm{KOLA}$ $1.974 \mathrm{EA}-0.665 \mathrm{GKKYK}+0.262 \mathrm{KUKYK}-$
1.451OBA - 0.289MLD olarak tespit edilmiştir. İkinci kanonik korelasyon katsayısın1 ise $\mathrm{Z}_{2}=$ $0.605 \mathrm{KD}_{1}-0.295 \mathrm{YK}_{1}-0.641 \mathrm{DK}_{1}$ ve $\mathrm{W}_{2}=$ $0.014 \mathrm{KA}-3.587 \mathrm{SKA}-0.733 \mathrm{KR}+1.655 \mathrm{KUYA}-$ $0.141 \mathrm{BA}-0.618 \mathrm{KOLA}+1.328 \mathrm{EA}+$ $0.633 \mathrm{GKKYK}-0.524 \mathrm{KUKYK}+0.545 \mathrm{OBA}+$ 0.282MLD olduğu saptanmıștır Üçüncü kanonik korelasyon katsayısin 1 ise $\mathrm{Z}_{3}=0.780 \mathrm{KD}_{1}$ $0.077 \mathrm{YK}_{1}-0.622 \mathrm{DK}_{1}$ ve $\mathrm{W}_{3}=-3.759 \mathrm{KA}+$ $24.272 \mathrm{SKA}+0.792 \mathrm{KR}-8.895 \mathrm{KUYA}-5.201 \mathrm{BA}-$ $6.906 \mathrm{KOLA}-4.340 \mathrm{EA}-0.239 \mathrm{GKKYK}+$ 0.628 KUKYK - 2.368OBA + 0.714MLD olduğu belirlenmiştir. Her hayvan için hesaplanan $Z_{1}$ ile $\mathrm{W}_{1}, \mathrm{Z}_{2}$ ile $\mathrm{W}_{2}$ ve $\mathrm{Z}_{3}$ ile $\mathrm{W}_{3}$ değerleri arasındaki kanonik korelasyon katsayıları sirasıyla 0.999, 0.977 ve 0.549 bulunmuş olup sadece birinci kanonik korelasyon istatistik olarak önemlidir $(\mathrm{P}<0.01)$. İkinci ve üçüncü kanonik korelasyon katsayısını oluşturan doğrusal kombinasyonlar arasındaki ilişki istatistik olarak önemsiz bulunmuştur ( $\mathrm{P}>0.05)$ (Tablo 3).

Besi ortasına ait kanonik değişkenlerden hesaplanan kanonik korelasyon katsayıları ve bunların önem seviyeleri Tablo 4'te verilmiştir. Akkaraman kuzularının besi başlangıcında alınan ultrasonik ölçümlere ait veri seti $\mathrm{X}_{1}$ ve karkas özelliklerine ait veri $\mathrm{Y}$ setine ait kanonik katsayıların oluşturduğu kombinasyonlar incelendiğinde; $\mathrm{Z}_{1}$ kanonik değişkeni üzerine sadece $\mathrm{YK}_{1}$ özelliği pozitif katkı sağlarken, $\mathrm{KD}_{1}$ ve $\mathrm{DK}_{1}$ özellikleri ise negatif bir katkı sağlamışlardır. W1 kanonik değişkeni üzerine KA, SKA, KR ve KUKYK özellikleri pozitif katkı sağlarken, KUYA, BA, KOLA, EA, GKKYK, OBA ve MLD özellikleri negatif etki sağlamıştır (Tablo 4).

Tablo 3. Akkaraman kuzularının besi başında alınan ultrasonik ölçümlerle elde edilen kanonik korelasyon katsayıları ve önem seyiyeleri

\begin{tabular}{cccccccc}
\hline Kanonik değişkenler & Korelasyon & $\left(\mathrm{R}^{2}\right)$ & Özdeğer & Wilks & $\chi^{2}$ & $\mathrm{~F}$ & $\mathrm{P}$ \\
\hline Z1W1 & 0.999 & 0.999 & 1229.567 & 0.000 & 79.812 & 7.027 & 0.008 \\
Z2W2 & 0.977 & 0.954 & 21.129 & 0.032 & 25.920 & 1.388 & 0.362 \\
Z3W3 & 0.549 & 0.301 & 0.431 & 0.699 & 2.692 & 0.191 & 0.981 \\
\hline
\end{tabular}

Z1W1: Besi başına ait birinci kanonik değișken, Z2W2: Besi başına ait ikinci kanonik değișken, Z3W3: Besi başına ait üçüncü kanonik değișken, P: Önemlilik düzeyi

Tablo 4. Akkaraman kuzularının besi ortasında alınan ultrasonik ölçümlerle elde edilen kanonik korelasyon katsayıları ve önem seyiyeleri

\begin{tabular}{cccccccc}
\hline Kanonik değişkenler & Korelasyon & $\left(\mathrm{R}^{2}\right)$ & Özdeğer & Wilks & $\chi^{2}$ & $\mathrm{~F}$ & $\mathrm{P}$ \\
\hline Z4W1 & 0.980 & 0.959 & 23.881 & 0.002 & 46.020 & 1.402 & 0.346 \\
Z5W2 & 0.931 & 0.867 & 6.528 & 0.054 & 21.899 & 0.990 & 0.554 \\
Z6W3 & 0.770 & 0.592 & 1.456 & 0.407 & 6.737 & 0.647 & 0.731 \\
\hline
\end{tabular}

Z4W1: Besi ortasında ait birinci kanonik değişken, Z5W2: Besi ortasında ait ikinci kanonik değişken, Z6W3: Besi ortasında ait üçüncü kanonik değişken,

Birinci kanonik korelasyon katsayısını (maksimum) oluşturan özelliklerin doğrusal kombinasyonu; $\mathrm{Z}_{4}=-0.455 \mathrm{KD}_{2}-0.819 \mathrm{YK}_{2}-$
$0.336 \mathrm{DK}_{2}$ ve $\mathrm{W}_{1}=1.468 \mathrm{KA}-9.229 \mathrm{SKA}-0.647 \mathrm{KR}$ $+2.912 \mathrm{KUYA}+0.728 \mathrm{BA}+1.751 \mathrm{KOLA}+$ $2.668 \mathrm{EA}+0.527 \mathrm{GKKYK}+0.052 \mathrm{KUKYK}+$ 
1.192OBA + 0.088MLD olarak saptanmıştır. İkinci kanonik korelasyon katsayısın 1 ise $\mathrm{Z}_{5}=0.918 \mathrm{KD}_{2}$ $0.615 \mathrm{YK}_{2}-0.294 \mathrm{DK}_{2}$ ve $\mathrm{W}_{2}=-1.180 \mathrm{KA}+$ $4.743 \mathrm{SKA}+0.589 \mathrm{KR}-1.072 \mathrm{KUYA}+0.116 \mathrm{BA}-$ $0.636 \mathrm{KOLA}-1.657 \mathrm{EA}-1.716 \mathrm{GKKYK}+$ 0.864KUKYK - 1.462OBA - 0.399MLD olduğu belirlenmiştir. Üçüncü kanonik korelasyon katsayısin 1 ise $\mathrm{Z}_{6}=-0.176 \mathrm{KD}_{2}-0.177 \mathrm{YK}_{2}+$ $0.965 \mathrm{DK}_{2}$ ve $\mathrm{W}_{3}=-1.690 \mathrm{KA}+13.851 \mathrm{SKA}+$ $0.902 \mathrm{KR}$ - 5.625KUYA - 2.472BA - 3.653KOLA $2.254 \mathrm{EA}-0.757 \mathrm{GKKYK}-0.347 \mathrm{KUKYK}$ 2.309OBA + 0.892MLD olduğu tespit edilmiştir. Her hayvan için hesaplanan $\mathrm{Z}_{4}$ ile $\mathrm{W}_{1}, \mathrm{Z}_{5}$ ile $\mathrm{W}_{2}$ ve $\mathrm{Z}_{6}$ ile $\mathrm{W}_{3}$ değerleri arasındaki kanonik korelasyon katsayıları sırasıyla $0.980,0.931$ ve 0.770 bulunmuş olup kanonik korelasyon katsayılarını oluşturan doğrusal kombinasyonlar arasındaki ilişki istatistik olarak önemsiz bulunmuştur $(\mathrm{P}>0.05)$ (Tablo 4).

Besi sonuna ait kanonik değişkenlerden hesaplanan kanonik korelasyon katsayıları ve bunların önem seviyeleri Tablo 5 'te verilmiştir. $\mathrm{Z}_{7}=$ $-0.507 \mathrm{KD}_{3}-0.354 \mathrm{YK}_{3}-0.893 \mathrm{DK}_{3}$ ve $\mathrm{W}_{1}=$ $0.091 \mathrm{KA}+3.383 \mathrm{SKA}+0.625 \mathrm{KR}-1.653 \mathrm{KUYA}-$ $1.295 \mathrm{BA}-0.850 \mathrm{KOLA}-0.955 \mathrm{EA}-0.818 \mathrm{GKKYK}$ $+0.105 \mathrm{KUKYK}-0.401 \mathrm{OBA}+0.235 \mathrm{MLD}$ olarak belirlenmiştir. İkinci kanonik korelasyon katsayısın1 ise $Z_{8}=-0.331 \mathrm{KD}_{3}-0.457 \mathrm{YK}_{3}+$ $0.569 \mathrm{DK}_{3}$ ve $\mathrm{W}_{2}=0.091 \mathrm{KA}+0.085 \mathrm{SKA}-$ $0.788 \mathrm{KR}+0.372 \mathrm{KUYA}-0.456 \mathrm{BA}-0.034 \mathrm{KOLA}$ $+0.125 \mathrm{EA}+0.213 \mathrm{GKKYK}-0.360 \mathrm{KUKYK}-$ 0.1890BA - 0.356MLD olduğu belirlenmiştir. Üçüncü kanonik korelasyon katsayısını ise $\mathrm{Z}_{9}=$ $1.176 \mathrm{KD}_{3}-1.095 \mathrm{YK}_{3}+0.240 \mathrm{DK}_{3}$ ve $\mathrm{W}_{3}=$ $1.560 \mathrm{KA}-14.146 \mathrm{SKA}-0.935 \mathrm{KR}+4.746 \mathrm{KUYA}+$ $3.228 \mathrm{BA}+3.539 \mathrm{KOLA}+3.326 \mathrm{EA}+$ 0.271 GKKYK - 0.128 KUKYK + $1.808 \mathrm{OBA}-$ $0.166 \mathrm{MLD}$ olduğu tespit edilmiştir. Her hayvan için hesaplanan $Z_{7}$ ile $W_{1}, Z_{8}$ ile $W_{2}$ ve $Z_{9}$ ile $W_{3}$ değerleri arasındaki kanonik korelasyon katsayıları sırasıyla $0.999,0.996$ ve 0.814 bulunmuş olup birinci ve ikinci kanonik korelasyonlar istatistik olarak önemlidir $(\mathrm{P}<0.05)$. Üçüncü kanonik korelasyon katsayısını oluşturan doğrusal kombinasyonlar arasındaki ilişki istatistik olarak önemsiz bulunmuştur ( $\mathrm{P}>0.05)$ (Tablo 5).

Akkaraman kuzularının besi sonunda alınan ultrasonik ölçümlere ait veri seti $X_{3}$ ve karkas özelliklerine ait veri $\mathrm{Y}$ setine ait kanonik katsayıların oluşturduğu kombinasyonlar incelendiğinde; $Z_{7}$ kanonik değişkeni üzerine tüm özelliklerin negatif bir katkı sağlamışlardır. $W_{1}$ kanonik değişkeni üzerine KA, SKA, KR, KUKYK ve MLD özellikleri pozitif katkı sağlarken, KUYA, BA, KOLA, EA, GKKYK ve OBA özellikleri negatif etki sağlamıştır. $Z_{8}$ kanonik değişkeni üzerine sadece $\mathrm{DK}_{3}$ özelliği pozitif katkı sağlarken, KD3 ve YK3 özellikleri ise negatif bir katk1 sağlamışlardır. $W_{2}$ kanonik değişkeni üzerine KA, SKA, KUYA, EA ve GKKYK özellikleri pozitif katk1 sağlarken, KR, BA, KOLA, KUKYK, OBA ve MLD özellikleri negatif etki sağladığ belirlenmiştir.

Akkaraman kuzularına ait standardize edilmiş besi başı ultrasonik ölçümleri içeren $\mathrm{X}_{1}$ setinin $\left(\mathrm{KD}_{1}, \mathrm{YK}_{1}, \mathrm{DK}_{1}\right)$ birinci kanonik değişkeni ultrasonik ölçümler setinin toplam varyansının \% 26.61'ini açıklarken, ikinci kanonik değişken ise \% 39.53'lük kısmını açıklamış olup, gereksizlik (redundancy) indeksi ise sirasiyla \% 26.59 ve \% 37.74 olduğu saptanmıştır. Y seti değişkenlerinin birinci kanonik değişkeni karkas özellikleri setinin toplam varyansının \% 4.55'ini, ikinci kanonik değişken ise \% 32.71'lik kısmını açıklamışken, redundancy (gereksizlik) indeksinin ise sirasiyla $\% 4.55$ ve \% 31.23 olduğu tespit edilmiştir. Bu şekilde iki kanonik değişkenin toplam varyansı açıklamada toplam $\mathrm{X}_{1}$ setinde $\% 66.14$ ve $\mathrm{Y}$ setinde ise \% 37.26'dır. Standardize edilmiş ultrasonik ölçümleri içeren $\mathrm{X}_{1}$ setinin birinci ve ikinci kanonik değişkeni ile standardize edilmiş $\mathrm{Y}$ seti özelliklerinin toplam varyansının sırasıyla \% 26.60 ve \% 37.70'ini, toplamda ise \% 64.30'unu açıklamıştır. Standardize edilmiş karkas özelliklerini içeren $\mathrm{Y}$ setinin birinci ve ikinci kanonik değişskeni ile standardize edilmiş $\mathrm{X}$ seti özelliklerinin toplam varyansının sırasıyla \% 4.60 ve \% 31.20'sini, toplamda ise \% 26.00'1n açıkladığı tespit edilmiştir.

Standardize edilmiş besi ortasındaki ultrasonik ölçümleri içeren $\mathrm{X}_{2}$ setinin $\left(\mathrm{KD}_{2}, \mathrm{YK}_{2}, \mathrm{DK}_{2}\right)$ birinci kanonik değişkeni ultrasonik ölçümler setinin toplam varyansının \% 34.70'ini, ikinci kanonik değişken ise \% 28.48'lik kısmını açıklamışken, gereksizlik (redundancy) indeksi ise sirasıyla \% 33.31 ve \% 24.71 olduğu belirlenmiştir. Y seti değişkenlerinin birinci kanonik değişkeni vücut ölçüleri setinin toplam varyansının \% 28.03'ünü, ikinci kanonik değişken ise \%4.89'luk kısmını

Tablo 5. Akkaraman kuzularının besi sonunda alınan ultrasonik ölçümlerle elde edilen kanonik korelasyon katsayıları ve önem seyiyeleri

\begin{tabular}{cccccccc}
\hline Kanonik değişkenler & Korelasyon & $\left(\mathrm{R}^{2}\right)$ & Özdeğer & Wilks & \multicolumn{1}{c}{$\chi^{2}$} & \multicolumn{1}{c}{$\mathrm{F}$} & $\mathrm{P}$ \\
\hline Z7W1 & 0.999 & 0.999 & 1427.465 & 0.000 & 99.821 & 17.915 & 0.000 \\
Z8W2 & 0.996 & 0.992 & 137.235 & 0.002 & 45.209 & 5.766 & 0.019 \\
Z9W3 & 0.814 & 0.661 & 1.957 & 0.338 & 8.125 & 0.870 & 0.606 \\
\hline
\end{tabular}

Z7W1: Besi sonunda ait birinci kanonik değişken, Z8W2: Besi sonunda ait ikinci kanonik değişken, Z9W3: Besi sonunda ait üçüncü kanonik değişken 
açıkladığı belirlenirken, gereksizlik (redundancy) indeksi ise sırasıyla \% 26.90 ve \% 4.244 olduğu tespit edilmiştir. Bu şekilde iki kanonik değişkenin toplam varyansı açıklamada toplam $\mathrm{X}_{2}$ setinde $\% 63.18$ ve $\mathrm{Y}$ setinde ise $\% 32.92$ olarak tespit edilmiştir. $\mathrm{X}_{2}$ setinin birinci değişkeni ile standardize edilmiş $\mathrm{Y}$ seti özelliklerinin toplam varyansinın sirasiyla \% 33.30 ve \% 24.70'ini toplamda ise \% 58.00'ını açıklamıştır. Y setinin birinci ve ikinci kanonik değişkeni ile $\mathrm{X}_{2}$ seti özelliklerinin toplam varyansının sırasıyla \% 26.90 ve $\% 4.20$ 'sini, toplamda ise \% 31.10'unu açıkladığı belirlenmiștir. Birinci ve ikinci kanonik değişkenler arası kanonik korelasyonun istatistik önemli olmamasına rağmen, toplam varyansı açıklamadaki başarısı gözlem âdetinin yetersizliğinden kaynaklandığı düşünülmektedir.

Standardize edilmiş besi sonundaki ultrasonik ölçümleri içeren $\mathrm{X}_{3}$ setinin $\left(\mathrm{KD}_{3}, \mathrm{YK}_{3}, \mathrm{DK}_{3}\right)$ birinci kanonik değişkeni ultrasonik ölçümler setinin toplam varyansının \% 30.08'ini, ikinci kanonik değişken ise \% 55.50'lik kısmını açıklarken, gereksizlik (redundancy) indeksi ise sirasıyla $\% 30.71$ ve \% 55.17 olduğu saptanmıştır. Y seti değişkenlerinin birinci kanonik değişkeni vücut ölçüleri setinin toplam varyansının \% 21.70'ini, ikinci kanonik değişken ise \% 27.30'luk kısmını açıklarken, gereksizlik (redundancy) indeksi ise sırasıyla \% 21.47 ve \% 27.39 olduğu belirlenmiştir. $\mathrm{Bu}$ şekilde iki kanonik değişkenin toplam varyansı açıklamada toplam $\mathrm{X} 3$ setinde $\% 85.58$ ve $\mathrm{Y}$ setinde ise \% 49.00 olarak belirlenmiştir. $X_{3}$ setinin birinci değişkeni ile standardize edilmiş $\mathrm{Y}$ seti özelliklerinin toplam varyansının sırasıyla \% 30.80 ve \% 55.10'unu, toplamda ise \% 88.90'1nı açıklamıştır. Y setinin birinci ve ikinci kanonik değişkeni ile $\mathrm{X}_{3}$ seti özelliklerinin toplam varyansının sırasıyla \% 21.70 ve \% 27.10’unu, toplamda ise \% 48.80'ini açıkladığı saptanmıştır.

Farklı zamanlarda alınan ultrasonik ölçülerin sağ seti, karkas özelliklerinin de sol seti oluşturarak belirlenen kanonik korelasyon katsayıları, tarım alanında daha önce yapılmış çalışmalarla örtüşmektedir (Tatar ve Eliçin, 2002; Keskin ve ark., 2004; Keskin ve Özsoy, 2004; Çankaya, 2005; Mendes ve ark., 2005; Çankaya ve Kayaalp, 2007; Çankaya ve ark., 2008, 2009; Özkan ve ark., 2008; Karabacak ve ark., 2009, 2019; Koşkan ve ark., 2011; Y1lmaz ve ark., 2011; Ural ve Barıtc1, 2013; Takma ve ark., 2017). Ayrıca, Yardımcı ve Özbeyaz (1999) ultrason ölçümlerinin yapıldı ̆̆ bütün vücut bölgelerinde MLD kesit alanı ile yağ derinliğinin ultrason ölçümleri ve karkas ölçümleri arasındaki korelasyonların oldukça yüksek düzeyde olduğunu; Hedrick (1983), ultrason yöntemiyle elde edilen yağ kalınlığı veya MLD alanı ile karkas kompozisyonu arasındaki ilişkinin, karkastan elde edilen gerçek ölçüler ile karkas kompozisyonu arasındaki ilişkiye benzerlik gösterdiğini rapor etmişlerdir. Literatürdeki bu bulgular çalışmamızı destekler niteliktedir.

Hayvanların canlı ağırlıkları ile karkas ağırlıkları arasında yüksek bir korelasyonun olduğu bilinmektedir (Keskin ve Dağ, 2009). Ultrasonik ölçümlerle gerek canlı ağırlıkları gerekse de karkas ağırlıkları arasında ilişkiler yüksek olmasa da istatistik olarak önem araz edebilir. Canlı ağırlık ile ultrasonik ölçümler arasındaki ilişki orta dereceli $(r=0.40-0.60)$ olmasına rağmen, istatistik olarak önemliyken $(\mathrm{p}<0.001)$ (Y1lmaz ve ark., 2011), çalışmamızda yapılan karkas ağırlığı ile ultrasonik ölçümler arasındaki ilişki de benzer sonuçlar elde edilmiştir.

\section{Sonuçlar}

Araştırma kapsamında ele alınan özellikler arasında besi baş1, ortası ve sonunda elde edilen ultrasonik ölçümlerin veri seti ile karkas özellikleri veri setleri arasındaki ilk iki kanonik korelasyonlar 0.930'dan fazla olduğu tespit edilmiştir. Bu kapsamda besi süresince ultrasonik ölçümleri kullanarak karkas özelliklerinin bir tahmini yapılmasına imkân sağlamaktadır.

Kuzular üstüne yapılan besi çalışmalarında da dikkat çeken husus dolaylı seleksiyon kriterlerinden yararlanılarak, karkas özellikleri ile ilişkili özelliklerin erken belirlenmesidir. Bundan dolay1 gerek 1slah faaliyeti yapanlar gerekse sürü yöneticileri hayvansal üretimde ilerleme sağlayabilmek amacıyla teknolojik ve istatistik yeniliklere gün geçtikçe daha fazla ilgi göstermektedirler. Bu kapsamda Türkiye'de de gerek teknolojik makine/ekipmanlar gerekse kanonik korelasyon gibi bazı istatistik metotların da kullanımı yaygınlaşacaktır.

$\mathrm{Bu}$ çalışmada Akkaraman ırkında farklı zamanlarda alınan ultrasonik ölçümlerin karkas özelliklerinin hangi zamanda ne kadarını açıklayabildikleri ortaya konulmaya çalışılmıştır. Besi başlangıcında birinci kanonik korelasyon katsayısının önemli, ikinci ve üçüncü kanonik korelasyon katsayılarının istatistik olarak önemsiz bulunması ve besi başında alınan ultrasonik ölçümlerin karkas özelliklerinin toplamda \% 63.30'luk kısmını açıklaması besi başında alınan ultrasonik ölçümlerin erken seleksiyon kriteri olarak kullanılabileceği göstermektedir. Besi ortasında alınan ultrasonik ölçümlerin karkas özellikleri toplamda \% 58.00'l1k kısmını açılarken, besi sonunda bu oran \% 88.90 olarak tespit edilmiştir. 
Kuzu besisi yapan yetiştiricilerin besi başında belirlenen ultrasonik ölçümleri alarak kuzuların besiye alınması yetiştiriciye hem ekonomik anlamda fayda sağlarken hem de pazar talebi karşılanarak bir katma değer sağlayacağ düşünülmektedir. Ayrıca kas ve deri altı yağ tabakası pazar talebini etkilediğinden besiye alınacak hayvanlarda doğru, hızlı ve objektif bir şekilde değerlendirilmenin yapılabilmesi için ultrasonik ölçümlerin koyun yetiştirme programlarında yer alması önem arz etmektedir.

\section{Kaynaklar}

Baggaley, A.R., 1981. Multivariate analysis: an introduction for consumers of behavioral research. Evaluation Review, 5(1): 123-131.

Croston, D., Owen, M.G., 1992. Ultrasonic evaluation of live sheep in breeding programmes. 43rd Annual Meeting of the EAAP, 13-17 September, Madrid.

Çankaya, S., 2005. Kanonik korelasyon analizi ve hayvancılıkta kullanımı. Doktora Tezi, Çukurova Üniversitesi Fen Bilimleri Enstitüsü, Adana.

Çankaya, S., Altop, A., Olfaz, M., Erener, G., 2009. Karayaka toklularında kesim öncesi ve kesim sonrası ölçülen bazı özellikler arasındaki ilişkinin tahmini için kanonik korelasyon analizi. Anadolu Tartm Bilimleri Dergisi, 24(1): 61-66.

Çankaya, S., Kayaalp, G.T., 2007. Estimation of relationship between live weights and some body measurements in German farm $\mathrm{x}$ hair crossbred by canonical correlation analysis. Hayvansal Üretim, 48(2): 27-32.

Çankaya, S., Yazgan, E., Kayaalp, G.T., Göçmez, Z., Serbester, U., 2008. Canonical correlation analysis for estimation of relationship between some body measurement at birth and six month period in Holstein Friesian calves. Journal of Animal and Veterinary Advances, 7(8): 953-958.

Ferreira, M.A., Purcell, S.M., 2009. A multivariate test of association. Bioinformatics, 25(1): 132-133.

Gürbüz, F., 1989. Değişken takımları arasındaki ilişkilerin kanonik korelasyon yöntemi ile araştırılması. Ankara Üniversitesi Ziraat Fakültesi Yayınları:1162, Ankara.

Hedrick, H.B., 1983. Methods of estimating live animal and carcass composition. Journal of Animal Science, 57(5): 1316-1327.

Hotelling, H., 1936 Relations between two sets of variables. Biometrika, 28: 321-377.

Johnson, A.R., Wichern, D.W., 2002. Applied Multivariate Statistical Analysis: Canonical Corelation Analysis, Fifth Edition, Prentice Hall, New Jersey.

Karabacak, A., Altay, Y., Aytekin, İ., 2019. Akkaraman ve ivesi kuzularının besi sonundaki bazı vücut ölçüleri ile ultrason ölçüleri arasındaki ilişkiler. Bahri Dă̆daş Hayvancılık Araştırma Dergisi, 8(2): 56-64.

Karabacak, A., Aytekin, İ., Keskin İ., Zülkadir, U., Boztepe, S., 2009. Akkaraman kuzularında besi başındaki canlı ağırlık ve çeșitli vücut ölçüleri ile karkas özellikleri arasındaki ilişkinin kanonik korelasyon yöntemi ile araștırılması. 1. Uluslararası 5. Ulusal Meslek Yüksek Okulları Sempozyumu, 27-29 Mayıs, Konya, s. 59-65.

Kerlinger, F.N., Pedhazur, E.J., 1973. Multiple Regression in Behavioral Research. New York, NY: Holt Rinehart \& Winston.

Keskin, I., Dag, B., 2009. Investigation of relationship amongst milk and wool yield traits of Awassi sheep by using canonical correlation analysis. Journal of Animal and Veterinary Advances, 8(3): 464-468.

Keskin, İ., Zulkadir, U., Dag, B., 2004. Canonical correlation analysis for studying the relationship between reproductive traits and milk yield traits of brown Swiss herd raised at the state farm of konuklar in konya province. Journal of Animal and Veterinary Advances, 3(12): 797-799.

Keskin, S., Kor, A., Başpınar, E., 2005. Akkeçi oğlaklarında kesim öncesi ve kesim sonrası ölçülen bazı özellikler arasındaki ilişki yapısının kanonik korelasyon analizi ile irdelenmesi. Tarm Bilimleri Dergisi, 11(2): 154-159.

Keskin, S., Ozsoy, A.N., 2004. Canonical correlation analysis and its application. Journal of Agricultural Sciences, 10(1): 67-71.

Kocabaş, Z., Kesici, T., Eliçin, A., 1998. Investigation of relationship amongst the various body measurements by using canonical correlation analysis. II. National Animal Science Congress, September 22-25, Uludağ University, Bursa, pp. 169-178.

Kor, A., Ertuğrul, M., 2000. Canlı hayvanda karkas kompozisyonu tahmin yöntemleri. Hayvansal Üretim, 41(1): 91-101.

Koşkan, O., Önder, E.G., Şen, N., 2011. Değişken setleri arası ilişkinin tahmini için kanonik korelasyon analizinin kullanımı I $\breve{g} d \imath r$ Üniversitesi Fen Bilimleri Enstitüsü Dergisi, 1(2): 117-123.

Mendes, M., Karabayır, A., Ersoy, I.E., Savas, T., 2005. The relationship among pre and post slaughter traits of American Bronze Turkey. Archives Animal Breeding, 48(3): 283-289.

Özdamar, K., 2004. Paket Programlar İle İstatistiksel Veri Analizi (Çok Değişkenli Analizler). Kaan Kitabevi, Eskişehir.

Özkan, M.M., Adak, S.M., Kocabaş, Z., 2008. An Investigation on the relationship betweenyield and canopy components in wheat (Triticum aestium) Tarm Bilimleri Dergisi, 14: 148-153.

Sharma, S., 1996. Applied Multivariate Techniques: Canonical Corelation, John Willey and Sons Inc., USA, pp. 391-418.

Simm, G., 1983. The use of ultrasound to predict the carcass composition of live cattle. A review. In Animal Breeding Abstracts, 51(12): 853-875.

Takma, Ç., Gevrekçi, Y., Özsoy, A.N., Çevik, M., 2017. Canonical correlation analysis on egg production traits of quails. Süleyman Demirel Üniversitesi Ziraat Fakültesi Dergisi, 12(1): 92-99.

Tang, C.S., Ferreira, M.A., 2012. A gene-based test of association using canonical correlation analysis. Bioinformatics, 28(6): 845-850. 
Tatar, A.M., Eliçin, A., 2002. Ile de france x akkaraman (G1) melezi erkek kuzularında süt emme ve besi dönemindeki canlı ağılık ve vücut ölçüleri arasındaki ilişkinin kanonik korelasyon metodu ile araştırılması. Tartm Bilimleri Dergisi, 8(1): 67-72.

Tatlıdil, H., 1996. Uygulamalı Çok Değişkenli İstatiksel Analiz, Cem Web Ofset, Ankara.

Tatsuoka, M.M., 1971. Multivariate Analysis: Canonical Corelation Analysis. John Willey and Sons Inc., USA, pp. 183-193.

Thompson, B., 1984. Canonical Correlation Analysis Uses and Interpretations. Sage University Paper, Newbury Park.
Ural, D.A., Barıtc1, İ., 2013. Determination of relationship between some udder and body traits of Holstein cows by canonical correlation analysis. Kocatepe Veteriner Dergisi, 6(1): 11-17.

Yardımcı, M., Özbeyaz, C., 1999. Use of ultrasound for grading carcass in live animals. Lalahan Hayvan Araştırma Enstitüsü Dergisi, 39(2): 69-82.

Yılmaz, O., Cemal, İ., Yılmaz, M., Karaca, O., Taşkın, T., 2011. Eşme yöresi kıvırcık melezi kuzularda pazarlama canlı ağırlığı ve bel gözü kası ultrason ölçümleri. 7. Ulusal Zootekni Bilim Kongresi, 14-16 Eylül, Adana, s. 508-517. 